\title{
Analysis on the Artistic Features and Themes of the Theater of the Absurd
}

\author{
Jiang Zhu \\ School of Foreign Languages, Changchun University of Science and Technology, Changchun 130022, China

\begin{abstract}
The Theater of the Absurd is a new form of drama after The Second World War. Playwrights of the Theater of the Absurd reveal the conditions of human beings' existence in modern society. This paper analyzes the artistic features and themes of the Theater of the Absurd.
\end{abstract}

Index Terms - artistic feature, theme, the Theater of the Absurd

\section{INTRODUCTION}

As a new form of drama, the Theater of the Absurd originated from France after The Second World War. Its name was coined by Martin Iselin in his book The Theatre of the Absurd, which was published in 1961. The playwrights of the Theater of the Absurd engaged in creating extremely grotesque plays both in form and contents, which revealed the conditions of human beings' existence in modern society. With the efforts of these playwrights, the Theater of the Absurd reached its peak from 1960s to 1970s and became popular not only in France but also in other countries. This paper analyzes the artistic features and themes of the Theater of the Absurd.

\section{The Artistic Features of THE THEATER OF THE AbSURD}

Artistic feature is an extensive category in literary field. It can be expressed in many ways by playwrights or writers. It is also a key point when we make a research on a literary work both at home and abroad. As a rule, every kind of theater has its own artistic features with regard to its special background and social demands. The Theatre of the Absurd is not an exception. In the Theater of the Absurd, multiple artistic features are used to express tragic theme with a comic form. The features include anti-character, anti-language, anti-drama and anti-plot.

\section{A. Anti-character}

In the Theaters of the Absurd, the characters are created with curious and grotesque personalities on the stages from the beginning to the end. It seems that the author specializes in shaping the characters with the sense of absurdity and tries to dig out their hopelessness to life and society. We know that in a traditional drama, characters are shaped with their own personalities in common sense. Their languages and behaviors should be reasonable and easy to understand. However, in the Theatre of the Absurd, people who abandon the normal sense and behaviors are completely shaped and described by the playwrights on the stages. Character, especially protagonist in the Theatre of the Absurd, has special personalities and nature. They sometimes talk to themselves continually or repeatedly. And most of the time their words and sentences are interrupted or disordered. There are not any regular rules to follow in their words. Therefore, common people will find that it is difficult to understand the character's words and behaviors. What's more, people in the Theater of the Absurd regard their own personalities as a formal case.

Let's take a retrospect in the typical example of Waiting for Godot. The two tramps are the protagonists in the play. From the beginning to the end of the drama, they speak continually. Sometimes they talk each other, and sometimes they talk to themselves. In addition, their words are difficult to understand for the readers and audience. Their conversations are messy without any regularity to obey. Sometimes they blurt out some words and sentences without any implication. They do not reveal any personalities or peculiarities to let us distinguish them, even without any distinction to identify them. We just know that they are two boys. We do not know other information about them, such as their homes, parents and even the times which they belong to. But if we compare them with other protagonists in other dramas, they are so extraordinary in personality. It gives us an illusion that they have not any personalities, but in fact, they are shaped with a kind of special personality by their authors (He, 1999). This kind of personality is different from that of the protagonists of traditional dramas. Sometimes when we read the Theater of the Absurd, we feel that we are confused by the protagonists.

To understand the Theater of the Absurd better, we may consider the definition of "absurd". The initial meaning of "absurd" is "out of harmony" in a musical context. Therefore its dictionary definition: "out of harmony with reason or propriety; incongruous, unreasonable, illogical". In common usage, "absurd" may simply mean "ridiculous", but this is not the sense in which it is used when we speak of the Theatre of the Absurd. In an essay on Kafka, Ionesco defined his understanding of the term as follows: "Absurd is that which is devoid of purpose....Cut off from his religious, metaphysical, and transcendental roots, man is lost; all his actions become senseless, absurd, and useless"(Chang, 2006). 
The Theater of the Absurd focuses on the central points and scope in a fundamental lyrical, poetic pattern. By abandoning subtlety of characterization and plot in the conventional sense, The Theatre of the Absurd gives the poetical element an incomparably greater emphasis. The play with linear plot depicts a development that presents a special poetic image. The play's extension in time is purely casual. So it has a lot of differences with the traditional dramas on the personalities and peculiarities of characters. The characters always have inconstant words, capricious behavior and odd ideas in their minds.

\section{B. Anti-language}

Language is an important constituent of literary work. The use of language is regarded as criterion to evaluate a writer's style and ability. Different writers form their own writing styles in their literary career. In traditional dramas, language is usually used in a logical order. When someone asks some questions, other people will give their answers. No matter whether the answers are true or false, they must obey certain logical order. But in the Theater of the Absurd, language has no fixed or settled form and regularities. The protagonists usually speak or talk in disorder. What the character has said sometimes is not the words that his partner has asked or wanted to get. Sometimes a character asks his partner something, but the partner says another thing that is irrelevant to what they are talking about. That is to say, language has no regularity to infer or obey. What they have said can not be understood by the audience. Just several minutes ago, the characters argue on the question of who will come. A moment later, they change to another irrelative subject, and finally you can not follow their thoughts, which will lead you misunderstand their mind. This special feature has caused people to understand the Theater of the Absurd with many difficulties. But the Theater of The absurd is still popular among people because it reflects the darkness of reality in modern society (Criffith, 1993).

If you ever read a drama that belongs to the Theater of the Absurd, you must realize that the language in this kind of drama is obscure and disorderly. Meanwhile, it has no regular rules to follow. You can not guess what the character will speak in his next statement because their language is irregular and unpredictable. The most important thing is that it never obeys ordinary sense and thoughts. It seems that sometimes people who are speaking in their own points are difficult to understand by others with common sense. So when you read one of the Theaters of the Absurd, you must prepare enough energy and wisdom to understand the obscure language.

In the "literary" theater, language remains the predominant component. But in the anti-literary theater, language is reduced to a very subordinate role. The Theater of the Absurd has gained the freedom of using language as merely one component of its multidimensional poetic imagery. By putting a scene in contrast to the action, by reducing it to meaningless patter, or by abandoning discursive logic for the poetic logic of association or assonance, the Theater of the Absurd has opened up a new dimension of the stage. In its devaluation of language, the Theatre of the Absurd is in harmony with the trend of our time. As George Steiner pointed out in two radio talks entitled The Retreat from the Word, the devaluation of language is characteristic not only of the development of contemporary poetry or philosophical thought but, even more, of modern mathematics and the natural sciences. "It is no paradox to assert", Steiner says, "that much of reality now begins outside language....Large areas of meaningful experience now belong to non-verbal languages such as mathematics, formulae, and logical symbolism. Others belong to 'anti-languages', such as the practice of nonobjective art or atonal music. The world of the word has shrunk." Moreover, the abandonment of language as the best instrument of notation in the spheres of mathematics and symbolic logic goes hand in hand with a marked reduction in the popular belief in its practical use. Language appears to be more and more in contradiction to reality. The trends of thought that have the greatest influence on contemporary popular thinking all show this tendency. Apart from the general devaluation of language in the flood of mass communications, the growing specialization of life has made the exchange of ideas on an increasing number of subjects impossible among members of difficult spheres of life who have each developed their own specialized jargons. When Ionesco summarizes the views of Antonin Artaud, he mentions that our knowledge becomes separated from life because our culture forms a "social" context into which we are not integrated. So the problem is to bring our lives back into contact with our culture, making it a living culture once again. To achieve this, we shall first have to kill "the respect for what is written down in black and white"... to break up our language so that it can be put together again in order to re-establish contact with "the absolute", or, as I should prefer to say, "with multiple reality"; it is imperative to "push human beings again towards seeing themselves as they really are" (Wu, 2004). That is why communication between human beings is so often shown in a state of breakdown in the Theater of the Absurd. It is merely a satirical magnification of the existing state of affairs. Language has run riot in an age of mass communication. It must be reduced to its proper function --- the expression of authentic content, rather than its concealment. But this will be possible only if man's reverence towards the spoken or written word as a means of communication is restored, and the ossified clichés that dominate thought are replaced by a living language that serves it. And this, in turn, can be achieved only if the limitations of logic and discursive language are recognized and respected, and the uses of poetic language acknowledged. Language is an extensive category in literary field which extends from words or sentences to paragraph.

In different type of literary forms, multiple languages are used. Moreover, different writers have their own style to apply languages. In the Theater of the Absurd, playwrights usually apply language skillfully and adequately. In order to achieve the sense of absurdity, they often use multiple artistic techniques to describe characters, including their behavior, language and the plot of the theater. 


\section{Anti-drama}

Drama usually has its own characteristics from its origins. Traditional dramas are easy to understand from its contents and themes, but the Theater of the Absurd is difficult to understand from many aspects. The Theatre of the Absurd appeared in 1950s, while traditional drama appeared several hundreds of years earlier. Traditional dramas and the Theater of the Absurd become popular in different times and the latter's emergence has its own special social background. They have their own representative playwrights respectively. Shakespeare and Bernard Shaw are the representative playwrights of traditional drama in Britain. While another group of playwrights, such as Beckett, Pinter and Albee belong to the Theater of the Absurd. The two different groups had formed different characteristics, but all of them obey the rules and forms of the ordinary drama. We cannot say that they are absolutely opposite. The two groups have intersections from language to artistic techniques. The Theater of the Absurd has some characteristics of the traditional dramas. Meanwhile, it has some unique characteristics, and all these characteristics hide beneath the surface of the absurd dramas. In traditional dramas, plot is clear and the contents are easy to grasp for common people. The main characters often are endowed with particular and typical behavior and personalities. So when you read or appreciate the drama, you will soon pick him or her up among the crowd. Another point is that the language in traditional drama is usually simple and suitable for common sense. For instance, though Shakespeare's plays were written many years ago, people can grasp their contents and enjoy them easily when they read them. That is why most people in our daily lives choose to read and appreciate traditional dramas. Though a lot of troubles and obstacles exist for people to understand the themes and language of the Theater of the Absurd, many researchers and specialists still try to explore it. In the Theater of the Absurd, the audience is confronted with characters whose motivations and actions remain largely incomprehensible. The more mysterious their actions and nature are, the less humanistic the characters become. Thus it is more difficult for us to understand the world from a normal point of view. The audience and readers fail to identify the characters in the play so it inevitably makes people feel humoristic and funny. If we identify a figure who loses his trousers, we feel embarrassed and shameful. However, if our tendency to identify has been inhibited by making such a character grotesque, we laugh at his predicament. We see what happens to the characters from the outside, rather than from their own point of view. With the incomprehensibility of the motivation, the unexplained and mysterious nature of the characters in the Theater of the Absurd effectively prevents us from identifying the characters. Such theater is a comic theater in spite of the fact that its subject-matter is somber, violent and bitter. That is why the Theater of the Absurd transcends the category of comedy and tragedy and combines laughter with horror.

\section{Anti-plot}

Plot is an indispensable constituent part of drama. Without it, a drama can not be called a drama in traditional dramas. Traditional dramas and the Theater of the Absurd have different plots. The difference is that the plot of the Theater of the Absurd is fractured and scattered. Generally speaking, traditional dramas are arranged in time, place or logical order. You can find the regular patterns and orders from time, place or logic in the theaters. Sometimes we can easily guess what the protagonist would do according to their words and sense. And sometimes the author will give us some hints to deduce the plot. Therefore, it is not difficult for us to read and enjoy the traditional dramas. What's more, sometimes you can guess the end of the drama. On the contrary, the Theater of the Absurd is surprising or obscure, and most of the time it has no end or results. For example, in Waiting for Godot, audience cannot guess the result of the play. They even do not know what the two boys will do or say in the next step. From the beginning to the end of this play, we do not know what they are waiting for and what they are talking about. We just know they are having an endless waiting and an endless talking. But we can not conclude that the Theater of the Absurd has no realistic essence because of its special plot. If we considered like that, there would no authors to continue to engage in this field to create new work for the eager readers. In Waiting for Godot, we can not get any essence and theme in it when we read it for the first time. In fact, emptiness in the characters' hearts is the essence of the play. Their words and behaviors without any exact purpose tell us the meaning of human being's existence. Nothingness is the essence. People are searching for their existence in modern society but in vain. It also observes the society in modern times from a special viewpoint. Therefore, it will bring us more consideration about our times with its themes and essence. Different themes and essence will form different types of dramas. The two different dramas appeared in different times in our society. In modern society, more and more people can not find their own status. Emptiness in their heart has formed an atmosphere. Thus anti-plot is an important feature of the Theater of the Absurd (Dietrich, 1989).

\section{THE THEMES OF THE THEATER OF THE ABSURD}

By analyzing the features of the Theater of the Absurd, I get a clear understanding about the theme. The existence of human being is full of suffering, cruelty and danger. Such existence forms an atmosphere of the devaluation of life in modern society. Facing this atmosphere, human beings lose themselves in it. Gradually, they feel lonely, frightened and despairing. Emptiness therefore becomes the true essence of their daily lives. Isolation and absurdity gradually fill their minds. The Theater of the Absurd actually reflects the reality of life in a bleak society. From it, we find that people in their daily lives are tired, obscure and aimless. The Theater of the Absurd is the product of modern society. People do not know the real meaning and destination of their lives. Some advanced writers have an insight in it and write it in a special form, which is called the Theater of the Absurd. At the beginning, it is difficult for the public to accept. When 
people appreciated the Bald Soprano on the stage for the first time, only several people were left in the theater. As time goes by, more and more people think highly of this kind of theater and consider that it is suitable for their lives.

Theater originally is used to show the reality on the stages. But everybody knows that reality is serious and full of dangers and adventures and it usually gives us tragic effects. Using comic form to end a play is a relative comfortable and moderate way. It can be accepted by common people more easily after comparing with other forms. When you begin to read the play, you may laugh at the characters and their words and behaviors. But after you finish reading the play, you may change your mind and consider its theme once again. You will consider that it is worthwhile to regard the play as a tragicomedy. Degradation and oppression should have been part of the tragic theme, but many playwrights in the Theater of the Absurd describe them in a happy and comic form. When you read this kind of play, you may feel ridiculous about them.

\section{A. The Crisis and Cruelty of Human Beings}

In the Theater of the Absurd, playwrights try to explore the crisis and cruelty of human beings. The Theater of the Absurd appeared in 1950s. At that time, economy developed very fast in western world. All kinds of new technologies were used in every field. People who wanted to survive must catch up with the step and variation of the society as soon as possible. If they could not keep pace with the speed of the society, they would be abandoned and lose themselves in it. Some of them were destined to be left and they could not find their status and identification. So it doomed that their minds were full of crisis and cruelty and usually their thoughts were strange and curious. Some pioneers wrote their minds and thoughts in the Theater of the Absurd to reveal their inner feelings. In contrast, traditional playwrights involve in more extensive themes, such as politics, economics and culture. Playwrights in the Theater of the Absurd regard the crisis and cruelty of human beings as one of its themes (Wang, 1995).

\section{B. The Dissimilation of the Society}

Dissimilation means that people regard the metamorphic things as normal things. Dissimilation of the society means that many abnormal things have appeared, what's more, these phenomena have been regarded as normal things. Disease, death and hunger are often regarded as the themes to discuss. Evil, crime and violence are often thought to be natural things in the society. When people come across these occasions, they would feel sad and sympathetic for the dead or the patients. But in the Theater of the Absurd, people consider it in an indifferent attitude. The world makes people feel unconcerned and even unmerciful. People no longer believe in any gods who can save them from the heaven. Material life is thought at the first place. Meanwhile, money is considered the most important thing in the world. Money is the first condition before people do everything. People live in a world where love and mutual assistance are meaningless. There is no love and trust among them.

\section{The Meaninglessness of the Existence of Human Beings}

To the two characters in Waiting for Godot, the meaning of their lives is just endless waiting. They could not find what they are waiting for. Their life is meaningless. They even could not find the essence of human existence. Though they live in the real world, their lives are ridiculous. In the Theater of the Absurd, playwrights express their true feelings to this world by means of the protagonist whom they have depicted in their plays. A play, in fact, is a mirror which reflects the real phenomena in the society. In the Theater of the Absurd the playwrights strive to express the senselessness of the human race and the inadequacy of the rational approach by the open abandonment of rational devices and discursive thought. While Sartre or Camus express the new content in the old convention, the Theater of the Absurd goes a step further in trying to achieve a unity between its basic assumption and the form in which these are expressed. They live in a real world, but they don't feel their existence. In fact, they are afraid of their existence, so they would rather put themselves in a confused or unconscious condition. Only when they don't realize their existence can they feel that they are alive. Most poor people exist and live in endless poverty, and life is terrible to them. If they consider their lives earnestly, their lives are miserable and painful. Only when they forget the reality can they abandon the suffering and feel their existence. But suffering is endless as long as they live, so they have to endure them from cradle to grave (Diao, 2008).

\section{The Isolation among People}

In the society described by the Theater of the Absurd, the relationship among people is measured through material and money. When they face some dangers and problems, few people come to help them. People who live in this society for a long time will feel lonely and indifferent. Human beings communicate with each other in a cold and detached attitude. Because of this, people gradually have less communication and would rather locked themselves in cages. And once more the chain reactions lead to a serious isolation among people. Therefore, the isolation is just like a snowball which is growing in people's heart. People seldom communicate with each other and hardly believe in each other. Because selfishness and fright fill their hearts, they are afraid that people who have higher social status than them will laugh at or look down upon them. So they try their best to cover and hide themselves under the surface of the material. And their desires and pursuits are put in their hearts silently even if they have rights to express them. In Waiting for Godot, the boys seem to be good friends, but the relationship between them is isolated and unconcerned. They cannot bring any warmth and comfort to each other. They communicate in just a few of words without much feeling and 
concern (Wang, 2001). The condition of little care or concern would make people feel lonely and helpless. Only in the Theater of the Absurd can this phenomenon express the original and true features of the society.

\section{CONCLUSION}

In the above parts I have analyzed the artistic features and themes of the Theater of the Absurd. The Theater of the Absurd has the features of anti-character, anti-language, anti-drama and anti-plot. When we analyze the themes of the Theater of the Absurd, we can find that it reflects the dissimilation of the society. In such kind of society, people are quite cruel to others and cause crisis in the society. People find that their lives are meaningless and they isolate themselves with the society. The Theater of the Absurd is a mirror to reflect the western world after World War II. Thus the Theater of the Absurd is valuable in making research on the western society.

\section{REFERENCES}

[1] Chang Yaoxin. (2006). A Survey of English Literature. Tianjin: Nankai University Press.

[2] Careth Criffith. (1993). Socialism and Superior Brains. London and New York: Routledge.

[3] Diao Keli. (2008). Classical Readings of English Literature. Beijing: Foreign Language Teaching and Research Press.

[4] He Qishen. (1999). History of British Drama. Shanghai: Yilin Press.

[5] Richard F. Dietrich. (1989). British Drama 1890-1950: A Critical History. Boston: Publishers.

[6] Wang Zuoliang \& Zhou Yuliang. (1995). History of British Literature in the $20^{\text {th }}$ Century. Beijing: foreign Language Teaching and Research Press.

[7] Wang Shouren. (2001). Selected Readings in British Literature. Beijing: Higher Education Press.

[8] Wu Weiren. (2004). History and Anthology of English Literature. Beijing: Foreign Language Teaching and Research Press.

Jiang Zhu was born in Changchun, China in 1971. He received his M.A. degree in English from Changchun University of Science and Technology, China in 2003.

$\mathrm{He}$ is currently an associate professor in School of Foreign Languages, Changchun University of Science and Technology. His research field is English and American literature. 